\title{
An original research paper on incidence and risk factors for surgical site infections following major abdominal surgeries in obstetrics and gynaecology
}

\author{
Shalini Mahana Valecha, Manisha Narayan Saswade*
}

Department of Obstetrics and Gynecology, ESI-PGIMSR, Andheri, Mumbai, Maharashtra, India

Received: 27 January 2017

Revised: 21 March 2017

Accepted: 23 March 2017

\section{*Correspondence:}

Dr. Manisha Narayan Saswade,

E-mail: manisha.saswade3@gmail.com

Copyright: (C) the author(s), publisher and licensee Medip Academy. This is an open-access article distributed under the terms of the Creative Commons Attribution Non-Commercial License, which permits unrestricted non-commercial use, distribution, and reproduction in any medium, provided the original work is properly cited.

\begin{abstract}
Background: Surgical site infections associated with substantial morbidity and mortality, increase in hospital stay and enhanced cost of health care. Objective of present study is to analyse the incidence of surgical site infections after major abdominal obstetrics and gynaecologic surgeries and risk factors for development SSIs.

Methods: It is observational study carried out at Department of Obstetrics and Gynaecology, ESI-PGIMSR at a teaching public hospital Mumbai, Maharashtra, India. It is a tertiary care centre and a teaching hospital. Women who had undergone abdominal surgery for various Obstetrics and Gynaecology indications.

Results: $7.3 \%$ of operated subjects had SSI. And significant risk factors are anemia, obesity hypoprotenemia, prolonged pre-operative hospital stay, Diabetes mellitus.

Conclusions: Post-operative abdominal wound infection represents a substantial burden of disease both for the patients and the healthcare services in terms of the morbidity, mortality and economic costs.
\end{abstract}

Keywords: Abdominal hysterectomy, Body mass index, Surgical site infection

\section{INTRODUCTION}

Surgical Site Infection (SSI) is defined as infection occurring within 30 days after a surgical procedure and affecting either the incision or deep tissues at the operation site. These infections may be superficial or deep or involving an organ space. ${ }^{1}$ There has been advance in SSI control practices which include improved operating room ventilation, sterilization methods, use of barriers, surgical technique and availability of antimicrobial prophylaxis. Despite, these SSIs remain common causes of morbidity and mortality among hospitalized patients.

The CDC's National Nosocomial Infections Surveillance (NNIS) system, established in 1970, monitors reported trends in nosocomial infections in U.S. acute-care hospitals. Based on NNIS system reports, SSIs are the third most frequently reported nosocomial infection, accounting for $14 \%$ to $16 \%$ of all nosocomial infections among hospitalized patients. ${ }^{2}$ During 1986 to 1996 , hospitals conducting SSI surveillance in the NNIS system reported 15,523 SSIs following 93,344 operations (CDC, unpublished data).

SSIs increase the rate of rehospitalization; the use of health care, diagnostic, and therapeutic resources; and hospital costs. The shorter the hospitalization time is for surgery, the lower the risk of infection. ${ }^{3}$ Notably, the risk factors for the development of SSIs may be related to the patients and the surgical procedures themselves.

According to Mangram et al, the main risk factors related to patient characteristics are age, poor nutritional status, 
diabetes mellitus, smoking, infectious focus at a distance, altered immune response, and long preoperative stays. ${ }^{1}$

The aim of our study was to analyse the incidence of SSIs and to identify associated risk factors in abdominal hysterectomy cases at a tertiary care hospital.

\section{METHODS}

A prospective study was carried out for a period of 18 months. This study was conducted on a total of 301 patients who underwent abdominal surgery in the Department of Obstetrics and Gynecology (OBGY) at a medical college attached to a tertiary care hospital.

During the study period, after obtaining informed consent to be a part of the study, data were collected as per a predesigned questionnaire for all the patients who underwent abdominal hysterectomy, myomectomy, explorative laparotomy, hysterotomy, salpingectomy in the OBGY department.

Risk factors, like patient characteristics (age, any comorbidity, indications of surgery, ASA score etc) and procedure characteristics (prophylactic antibiotics, postoperative antibiotics, date of surgery, type of anesthesia, type of wound, duration of surgery in minutes, necessary pre op investigations) were analyzed to predict SSIs.

After surgery, the patients were monitored daily for any signs of SSIs as per the CDC (Centre for Disease Controland Prevention) definition. We usually discharge patients on day 3 or day 4 of surgery and call them on day 8 or day 10 of surgery. Patients were followed after discharge on OPD (Out Patient Department) basis twice or thrice weekly for up to 30 days to have a checkup for any signs of SSIs. Samples were collected from these patients and immediately transported to the Microbiology laboratory for culture.

Patients with SSI were identified as per the following criteria. $^{4}$

- Infection occurring in the first post-operative week

- Involving skin and subcutaneous tissue at surgical site with any one of the following:

a. Purulent discharge

b. Organisms isolated from fluid/tissues of superficial incision

c. At least one sign of inflammation (indurations, erythema, local rise of temperature, excess pain in the incision site.)

d. Wound deliberately opened by the surgeon for drainage

e. Surgeon declares that the wound is infected due to overt signs of inflammation and or discharge from suture line pointing towards SSI.

\section{Exclusion criteria}

- Patients undergoing vaginal surgeries

- Cases operated outside our hospital

- Patients not giving consent to participate in the study

\section{Variables studied}

- $\quad$ Body mass index (BMI)

- $\quad$ Pre-operative Hemoglobin level

- Co-morbidities hypertension/diabetes mellitus/renal disease/bronchial asthma/Thyroid dysfunctions or any other

- Pre-surgery hospital stay i.e. interval between day of admission and day of surgery

- Duration of surgery (from incision to closure)

- Expertise and experience of operating surgeon

- Type of incision

Pre-operative antibiotics were usually administered half hour before surgery to all the patients. After surgery, the patients were monitored daily for any signs of SSIs as per the CDC (Centre for Disease Controland Prevention) definition4. Patients were followed after discharge on OPD (Out Patient Department) basis on a case to case basis as the need be for up to 30 days to have a checkup for any signs of SSIs. Samples were collected from these patients and immediately transported to the Microbiology laboratory for culture.

\section{RESULTS}

Surgeries performed on the women at Department of Obstetrics and Gynaecology, ESI-PGIMSR Obstetrics and Gynaecology indications. 22 cases $(7.30 \%)$ of the study population of 301 patients) developed SSIs. The diagnosis of SSIs occurred between the 5th and $18^{\text {th }}$ postoperative days.

Table 1: Incidence of SSIs in cases of abdominal surgeries.

\begin{tabular}{|ll|}
\hline Total cases of abdominal surgeries & 301 \\
\hline SSIs among all cases & 22 \\
\hline Total incidence & 7.30 \\
\hline
\end{tabular}

Table 2: Incidence of SSIs according to type of surgery.

\begin{tabular}{|llll|}
\hline Procedure & $\begin{array}{l}\text { No. of } \\
\text { cases }\end{array}$ & $\begin{array}{l}\text { Infected } \\
\text { cases }\end{array}$ & $\%$ \\
\hline Abdominal hysterectomy & 250 & 16 & 6.4 \\
\hline Exploratory laparotomy & 32 & 05 & 15.62 \\
\hline Hysterotomy & 05 & 0 & 0 \\
\hline Myomectomy & 08 & 01 & 12.5 \\
\hline Salpingectomy & 06 & 0 & 0 \\
\hline
\end{tabular}

The most prevalent characteristics of the surgical wounds of women with SSIs (i.e., symptoms and signs of SSIs) 
were draining purulent secretion, localized pain, in excess of that associated with incisions, redness, bruising, and swelling. The highest incidence of SSIs was observed among women aged 60 to 70 years of age $(46.66 \%)$. The lowest incidence of SSIs was observed in women between 30 to 40 years of age $(2.56 \%)$. Among women with SSIs risk factors were obesity $(66.66 \%)$, anemia (23.68\%), diabetes mellitus (19.35\%) and hypoproteinemia $(18.18 \%)$.

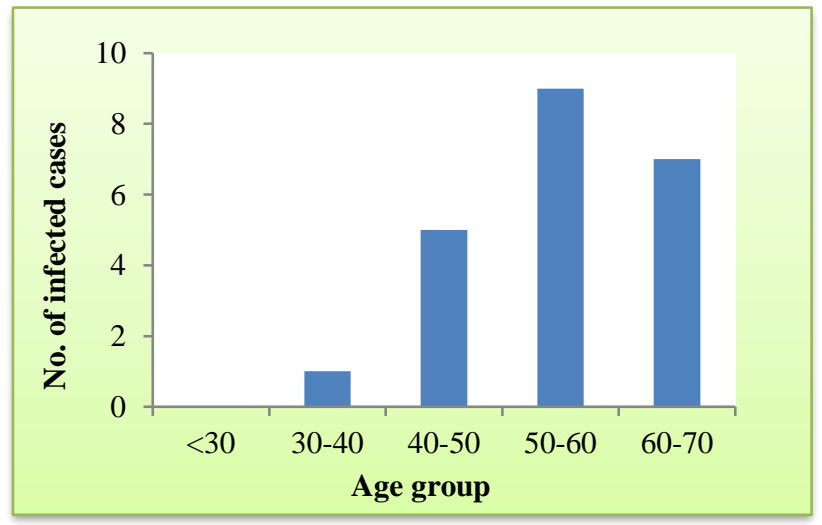

Figure 1: Incidence of SSSs in relation to age group.

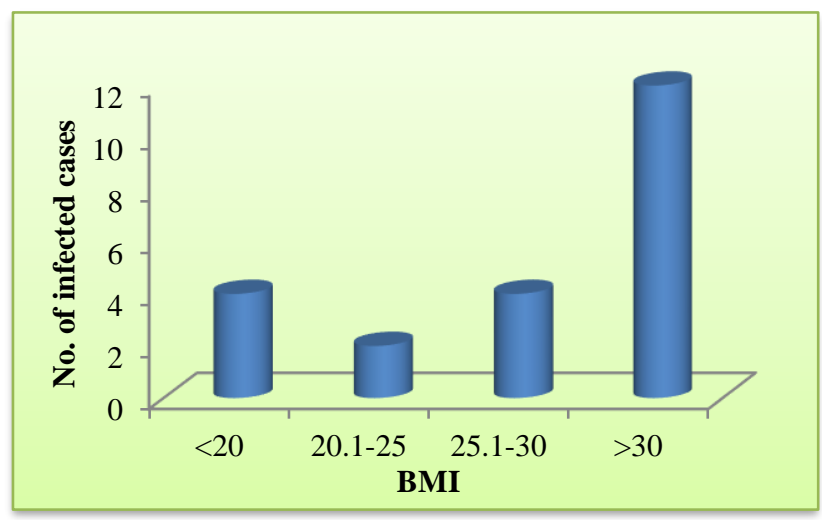

Figure 2: Incidence of SSIs in relation to BMI.

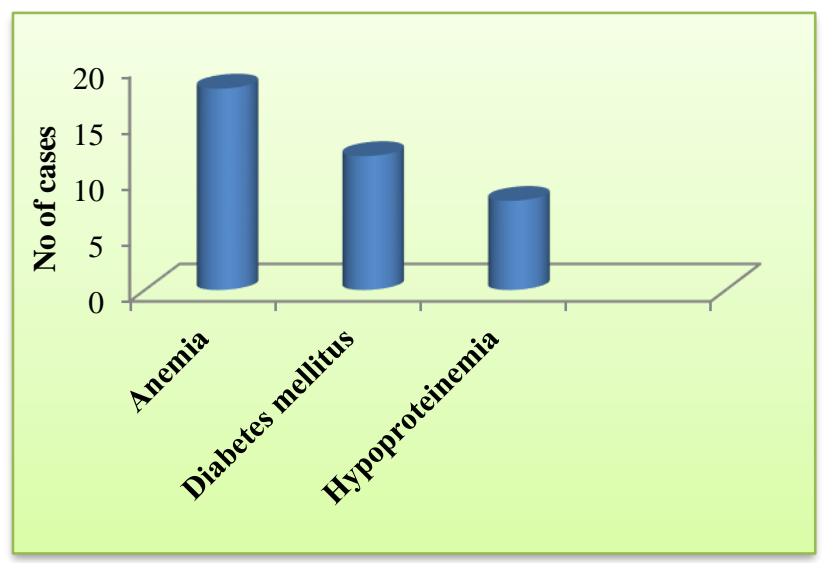

Figure 3: In incidence of SSIs in relation to high risk factors.

\section{DISCUSSION}

Rates of surgical site infection (SSI) reported from individual institutions have ranged from $0 \%$ to $15 \%$, depending on the indication for the operation, the site, the approach, and the use of instrumentation. ${ }^{5}$ The overall wound infection rate obtained by our study was $7.30 \%$. Bangal VB et al found that highest infection rate for laparotomies $11.4 \%$ followed by $10.94 \%$ for abdominal hysterectomies. ${ }^{6}$ The infection rate was highest for laprotomy $15.62 \%$ (5/32), followed by myomectomy $12.5 \%(1 / 8)$, abdominal hysterectomy $6.4 \%(16 / 250)$. This could be explained by laparotomies were done for malignancy patients which were old age, immunocompromised, and prolonged pre-operative hospital stay and duration of operation.

Table 3: Incidence of SSIs in relation to pre op hospital stay.

\begin{tabular}{|llll|}
\hline $\begin{array}{l}\text { No. of } \\
\text { days }\end{array}$ & $\begin{array}{l}\text { No. of } \\
\text { cases }\end{array}$ & $\begin{array}{l}\text { Infected } \\
\text { cases }\end{array}$ & Incidence \\
\hline $1-5$ & 275 & 15 & 5.45 \\
\hline $5-10$ & 24 & 6 & 25 \\
\hline $11-15$ & 2 & 1 & 50 \\
\hline
\end{tabular}

The relationships between age and SSIs are frequently reported in the literature and are attributable to immune senescence during the physiological process of aging which increases the risk of infection. Studies confirm that women aged 50 years and over have a 3-fold higher risk of SSIs than younger women16-19. In this study, we found that infection rate was highest $(46.66 \%)$ in extremes of age (51- 60 years). This was because increasing age is correlated with greater likelihood of certain chronic conditions, malnutrition and a fall in the body's immunological efficiency, causing more extensive SSI. ${ }^{7}$ The rate of SSI was lowest $(2.56 \%)$ in $30-40$ years of age where the immunity is good. Barwolff et al (2006) found that maternal ages of $<25$ years and $>45$ years were significant risk factors for overall SSI in a multiple logistic regression analysis. ${ }^{8}$ Johnson et al found increasing age a significant risk factor for overall SSIs. ${ }^{9}$ In the present study, an increased BMI was seen to influence the outcome of surgery in terms of an increased rate of infection. One reason being a decrease in blood circulation in fat tissues is associated with increase in infection rate. Similar results were found in other studies. $^{10}$

Table 4: Incidence in relation to duration of surgery.

\begin{tabular}{|llll|} 
Duration & $\begin{array}{l}\text { No of } \\
\text { cases }\end{array}$ & $\begin{array}{l}\text { Infected } \\
\text { cases }\end{array}$ & Percentage \\
\hline$<2 \mathrm{hrs}$ & 249 & 8 & 3.4 \\
\hline$>2 \mathrm{hrs}$ & 52 & 14 & 26.92 \\
\hline
\end{tabular}

In a retrospective study of risk factors in 15 cases of postsurgical wound infection by John et al in Messologi, COPD was noticed in 10 cases $(66.66 \%)$, obesity in 6 
cases $(40 \%)$, malnutrition in 5 cases $(33.33 \%)$, anaemia in 6 cases $(40 \%)$, diabetes in 6 cases $(40 \%)$, history of previous radiotherapy or chemotherapy in 6 cases $(40 \%)$ and 3 cases $(20 \%)$ were on steroids. ${ }^{11}$ Waqar et al from Pakistan institute of medical sciences studied 117 cases from $1^{\text {st }}$ January 2002-31 ${ }^{\text {st }}$ Dec 2002, out of which obesity was found in $13 \%$, anaemia in $17 \%$ cases, undernutrition in $13 \%$ cases and Malignancies in $15 \%$ of cases. ${ }^{12}$ In the present study the common risk factors found were obesity, anaemia $23.68 \%$, undernutrition in $18.18 \%$, diabetes in $19.35 \%$.

Kowli et al found an infection rate of $17.4 \%$ when preoperative stay was 0-7 days, and an infection rate of $71.4 \%$ with a preoperative stay of more than 21 days. ${ }^{13}$ Anvikar et al demonstrated that preoperative hospital stay predisposed an individual to $1.76 \%$ risk of acquiring an infection. With an increase in preoperative stay, the risk increased proportionally.

A preoperative stay of one week increased the risk rate to $5 \%{ }^{14}$. In the present study wound infections are highest when pre operative hospital stay is more than 5 days.

Devjani et al found $53.3 \%$ of patients with prolonged duration of surgery exceeding 45 minutes got infected. ${ }^{15}$ Lilani et al found that infection rate of $1.47 \%$ for operations lasting for 45 minutes to $2 \mathrm{hr}$ and infection rate of $38.46 \%$ for procedures lasting for more than 2 hrs. ${ }^{16}$ In present we found infection rate of $26.92 \%$ for procedures lasting for more than $2 \mathrm{hrs}$ and $3.4 \%$ for procedures lasting for less than $2 \mathrm{hrs}$.

\section{CONCLUSION}

Post-operative abdominal wound infection represents a substantial burden of disease both for the patients and the healthcare services in terms of the morbidity, mortality and economic costs. Although surgical wound infections cannot be completely eliminated, a reduction in the infection rate to a minimal level may have significant benefits. This may be achieved by meticulous surgical techniques, minimizing the duration of operation, proper sterilization, hygienic operation theatres and ward environments. Counselling patients in maintaining good personal hygiene and dietary advice towards improvement in general health is an exercise worth doing. Patients must understand that surgeons operate, sutures approximate, but ultimate healing is done by a well nourished body and positive mind set.

Funding: No funding sources Conflict of interest: None declared

Ethical approval: The study was approved by the Institutional Ethics Committee

\section{REFERENCES}

1. Mangram AJ, Horan TC, Pearson ML, Silver LC, Jarvis WR. Guideline for prevention of surgical site infection. Centers for Disease Control and Prevention (CDC) Hospital Infection Control Practices Advisory Committee. Am J Infect Control. 1999;27:97-132.

2. Emori TG, Gaynes RP. An overview of nosocomial infections, including the role of the microbiology laboratory. Clin Microbiol Rev. 1993;6(4):428-42.

3. Martins MA, França E, Matos JC, Goulart EMA. Post-discharge surveillance of children and adolescents treated for surgical site infections at a university hospital in Belo Horizonte, Minas Gerais State, Brazil. Cad Saude Publica 2008;24:1033-41.

4. CDC//NHSN surveillance definition of health care associated infection and criteria for specific types of infections in the acute care setting. Am $\mathrm{J}$ Infect Diseas Control. 2009;36:309-15.

5. Olsen MA, Nepple JJ, Riew KD, Lenke LG, Bridwell KH, Mayfield $\mathrm{J}$ et al. Risk factors for surgical site infection following orthopaedic spinal operations. J Bone Joint Surg Am. 2008;90:62-9.

6. Bangal VB, Borawake SK, Shinde KK, Gavhane SP. Study of Surgical Site infections following gynaecological surgery at tertiary care teaching hospital in Rural India. Int $\mathbf{J}$ Biomed Res 2014;5(2):113-6.

7. Mansour RS, Ibrahimpoor M, Kashani A, Jafarian A. Abdominal surgical site infections: incidence and risk factors at an Iranian teaching hospital. Bio Med Central Surg. 2005;5(2):1-5.

8. Barwolff S, Sohr D, Geffers C, Brandt C, Vonberg $\mathrm{RP}$, Halle $\mathrm{H}$ et al. Reduction of surgical site infections after Caesarean delivery using surveillance. J of Hosp Inf. 2006;64: 156-61.

9. Johnson A, Young D and Reilly J. et al. Caesarean section surgical site infection surveillance. $\mathrm{J}$ of Hosp Inf. 2006; 64(1):30-5.

10. Hoer J, Lawong G, Klinge U, Schumpelick V: Factors influencing the development of incisional hernia. A retrospective study of 2,983 laparotomy patients over a period of 10 years. Chirurg 2002, 73:474-480

11. John S. Wound dehiscence: is still a problem in the 21th century: a retrospective study. World Journal of Emergency Surgery 2009; 4:12 doi:10.1186/1749 7922-4-12.

12. Waqar Study of wound infection in Pakisthan institute of medical sciences. Ulus trauma, 2001; 7(2):96-9.

13. Kowli SS, Nayak MH, Mehta AP, Bhalerao RA (1985). Hospital infection. Indian J. Surg. 48: 47586.

14. Anvikar AR, Deshmukh AB, Karyakarte RP, Damle AS, Patwardhan NS, Malik AK, Bichile LK, Bajaj JK, Baradkar VP, Kulkarni JD, Sachdeo SM (1999). A one year prospective study of 3,280 surgical wounds. Indian J. Med. Microbiol. 17: 129-32.

15. Devjani. Risk factors analysis and microbial etiology of surgical site infections following lower segment cesarean section. Int J Antibiotics. 2013;283025:1. 
16. Lilani SP, Jangale N, Chaudhary A, Daver GB. Surgical site infections in clean and contaminated surgeries.Indian J Med Microbiol 2005; 23 (4):24952 .
Cite this article as: Valecha SM, Saswade MN. An original research paper on incidence and risk factors for surgical site infections following major abdominal surgeries in obstetrics and gynaecology. Int J Reprod Contracept Obstet Gynecol. 2017;6:1859-63. 